\title{
Dyspnoea of cardiac origin in 67 year old men: (2) relation to diastolic left ventricular function and mass The study of men born in 1913
}

\author{
KENNETH CAIDAHL, * HENRY ERIKSSON, $†$ MARIANNE HARTFORD, \\ JOHN WIKSTRAND* INGEMAR WALLENTIN, * ANDERS ARVIDSSON,§ \\ KURT SVÄRDSUDD†
}

From the Gothenburg University, Department of Clinical Physiology, Sahlgren's Hospital, ^ Section for Preventive Medicine at the Department of Medicine, Östra Hospital, $\dagger$ Section of Cardiology at the Department of Medicine I, $\ddagger$ and Department of Clinical Data Processing,§ Sahlgren's Hospital, Gothenburg, Sweden

SUMMARY The relation of cardiac dyspnoea to diastolic left ventricular dysfunction was examined in a sample of 67 year old men from the general population of Gothenburg, Sweden. Forty two men with cardiac dyspnoea and 45 controls were selected from the screened cohort of $644 \mathrm{men}$. $\mathrm{M}$ mode echocardiography, apexcardiography, and phonocardiography were used to evaluate heart sounds, diastolic time intervals, aortic root motion (atrial emptying index); peak rate of change in left ventricular dimension, left atrial and ventricular size; and left ventricular mass. There was a significant relation between dyspnoea grade and left ventricular mass and posterior wall thickness. Dyspnoea grade also correlated significantly with the amplitude of the rapid filling wave and the third heart sound, atrial emptying index and left atrial size, the pulmonary component of the second heart sound, and the dimension of the right ventricle. In mild to moderate dyspnoea fractional shortening was normal, but posterior wall thickness and left atrial dimension were increased. The time from the second heart sound to the $O$ point of the apexcardiogram, adjusted for heart rate, was significantly prolonged in mild to moderate dyspnoea, but not in severe dyspnoea. There was a significant decrease of rate adjusted isovolumic relaxation time, probably secondary to altered loading conditions, in severe dyspnoea, but not in mild to moderate dyspnoea. When the effect of systolic function was excluded multivariate analyses showed that the relation between dyspnoea grade and left atrial dimension persisted.

The finding that diastolic abnormalities of the heart contributed to the generation of cardiac dyspnoea may have implications for treatment.

The introduction of non-invasive methods has made detailed studies of cardiac function possible not only in the clinical situation but also in the general population. ${ }^{12}$ Because early detection and treatment of cardiac dysfunction may be the best way to reduce the high mortality from congestive heart failure, ${ }^{3}$ practicable methods of early detection would be valuable.

In recent years there has been an increase in the interest in, and understanding of, diastolic left

Requests for reprints to Dr Kenneth Caidahl, Department of Clinical Physiology, Sahlgren's Hospital, S-413 45 Gothenburg, Sweden.

Accepted for publication 29 June 1987 ventricular function as an important part of cardiac performance. ${ }^{4}$ Diastolic abnormalities of cardiac function often occur early in disease processes such as hypertension ${ }^{2}$ and coronary heart disease. $^{56}$ Furthermore, it has been shown that impaired diastolic function is frequent in non-dilated coronary diseased hearts ${ }^{7}$ and may cause congestive heart failure despite normal systolic function. ${ }^{89}$

The prevalence of diastolic abnormalities has been measured in patients with primary hypertension, coronary heart disease, and overt congestive heart disease, but not in the general population. We have already studied dyspnoea of presumed cardiac origin in a random sample of 67 year old men and the 
relation of this symptom to regional ${ }^{10}$ and systolic ${ }^{11}$ left ventricular function. In the present study we investigated whether there was any association between dyspnoea of presumed cardiac origin and impaired diastolic function in the same group of men.

\section{Patients and methods}

\section{SCREENED POPULATION}

The screened population ${ }^{12}$ and the study population $^{1011}$ have been described in detail elsewhere. Please see our earlier paper. ${ }^{11}$ Dyspnoea was measured according to the World Health Organisation's modification of the questionnaire proposed by the British Medical Research Council's Committee on the Aetiology of Chronic Bronchitis. ${ }^{13}$ Information on sustained myocardial infarction was obtained from the Myocardial Infarction Register covering the city of Gothenburg. Information on cardiac disease, chronic bronchitis, and smoking habits was obtained by questionnaire. ${ }^{12}$

\section{STUDY POPULATION}

Based on the dyspnoea questionnaire, the medical history, and a physical examination, 49 men were considered to have dyspnoea and a possible underlying cardiac disease but no signs or symptoms of obstructive pulmonary disease. Seven of these men were excluded from the study. ${ }^{11}$ A control group of 51 men without dyspnoea was selected and 45 were eventually included in the study. Full details of these men are given in our earlier paper. ${ }^{11}$. The control group was divided into two subgroups. Those in group $A(n=14)$ had no hypertension treatment, no atrial fibrillation, no angina pectoris, no myocardial infarction, and no other known cardiac disease or akinetic segments on cross sectional echocardiography. Group B was made up of the remaining men $(\mathbf{n}=31)$. Six men in the control group $\mathbf{B}$ were on $\beta$ blockers (none in group $A$ ), while no man in any of the control groups was on digitalis or diuretics.

\section{METHODS}

The investigations and coding of results are described in our earlier paper. ${ }^{11}$ Electrocardiograms were classified according to the Minnesota Code. ${ }^{13}$

\section{Non-invasive heart measurements}

Detailed descriptions of our methods and recording techniques are given elsewhere. ${ }^{1214}$ and we followed the protocol of our earlier study. ${ }^{11}$

$M$ mode echocardiographic left ventricular diameter, interventricular septal thickness, and posterior wall thickness were all measured at the $P$ and at the $Q$ waves of the electrocardiogram (lead II), and when the distance between the septum and posterior wall (at or before the initial vibrations of the second $\stackrel{\stackrel{M}{C}}{C}$

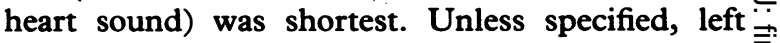
ventricular dimension as well as septal and posterior $\stackrel{9}{\stackrel{9}{+}}$ wall thickness refer to the value at the $Q$ wave. The $\bar{c}$ right ventricular dimension was measured at the 흘 electrocardiographic $Q$ wave.

We calculated the peak rate of change of left $\stackrel{\mathbb{Q}}{\Omega}$ ventricular dimension before atrial contraction and the peak rate of posterior wall thinning during the $\vec{A}$ same period. The time from minimum left ventricular dimension to peak left ventricular filling and $\vec{\omega}$ the time from the most anterior excursion of the $\stackrel{\rho}{\rho}$ posterior left ventricular wall to posterior wall peak thinning were measured. Measurements were per- of formed with a digitising table (Summagraphics ID- $\omega$ 2CTR-TAB17, Connecticut, USA) a microcom- $\omega_{N}$ puter (Professional-380, Digital Equipment), and a specially designed computer program.

The left ventricular mass was calculated by the cube formula, assuming a left ventricular muscle shell with the thickness of the mean of the septum $\frac{\hat{\rho}}{3}$ and posterior wall. The Teichholtz formula, ${ }^{15}$ was $\vec{A}$ applied in a similar manner. Left ventricular mass $(\mathbf{g}) \stackrel{\bigodot}{\bigodot}$ was estimated by subtracting the volume of the cavity $\propto$ from that of the total left ventricle and multiplying by 1.05 , which is the specific gravity of heart muscle. The left ventricular mass was adjusted for body surface area. To validate the methods we compared the mass measurements at the $P$ wave, $Q$ wave, and $\propto$ end systole. Both formulas gave good correlations $(\mathbf{r} \overrightarrow{\overrightarrow{0}}$ $=0.98$ to $\mathrm{r}=0.94$ ), but because the mean values by 3 the cube formula were less variable we used this formula for the present report. Fractional shortening was calculated as left ventricular (end diastolic - end systolic)/end diastolic dimensions.

The left atrium was measured at aortic valve closure or at the initial sibrations of the aortic 3 . component of the second heart sound. The mesurements were adjusted for body surface area.

The atrial emptying index ${ }^{816}$ was calculated from 0 the posterior aortic wall motion as an estimate of early left ventricular filling properties (fig 1). The point at which the aortic root had reached its most $\sim$ anterior position was taken as being equivalent to mitral valve opening. We measured the distance from $\tilde{O}$ this point to that at which atrial contraction had its $\underset{\mathrm{N}}{\mathrm{N}}$ initial effects on the aortic wall. The first third of this 0 distance was marked. The atrial emptying index 0 represents the relation between the aortic wall $\mathbb{\Phi}$ motion during this first third of the distance and the $\stackrel{\rho}{+}$ aortic wall motion during the full distance measured. In the case of atrial fibrillation, the initial QRSO activity was used to mark the end of the passive filling period.

The isovolumic relaxation time (A2 - Mo) was calculated as the distance from the initial vibrations 

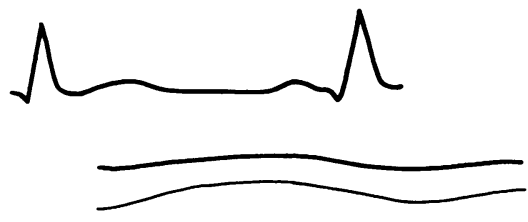

Anterior aortic wall

Aortic valve

Posterior aortic wall

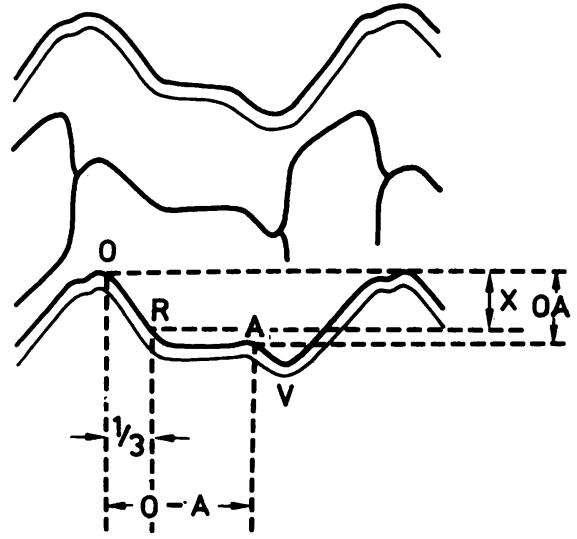

Posterior left atrial wall
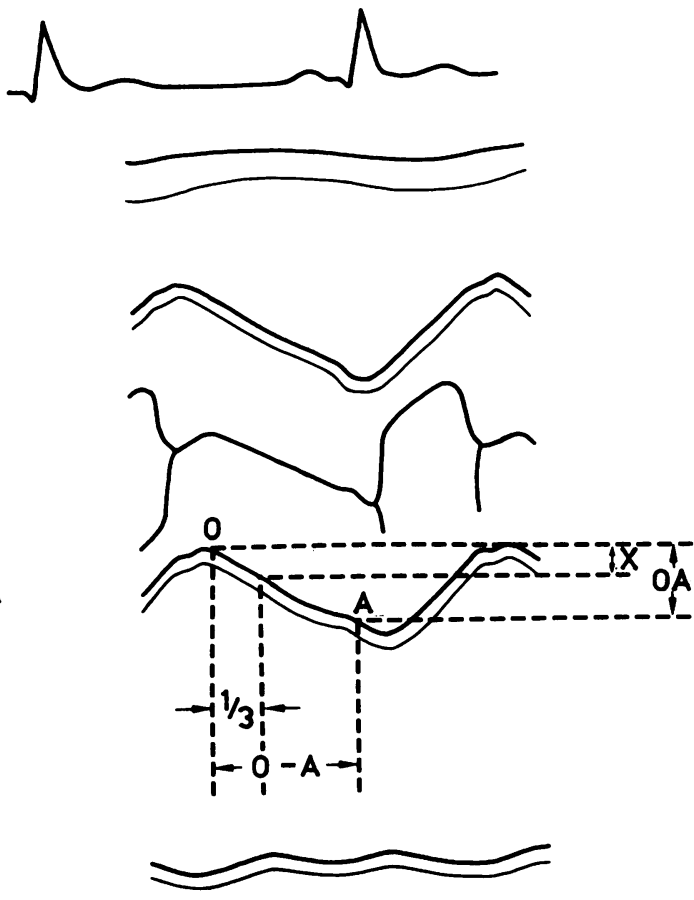

Fig 1 The atrial emptying index represents the ratio $(X / O A)$ between aortic root motion during first third (O-R) of the passive left ventricular filling period and that of the whole period $(O-A)$. The normal situation is shown in the left part of the figure. The right part of the figure shows a decreased $X / O A$.

of the aortic component (A2) of the phonocardiogram recorded on the $M$ mode tracing of the mitral valve to the mitral valve opening.

We used the mean value for five beats measured on the apexcardiograms. From simultaneous recordings of the apexcardiogram, phonocardiogram, and electrocardiographic lead II we measured the rapid filling wave and adjusted for the total amplitude of the apexcardiogram $(\mathrm{RFW} / \mathrm{H}) .{ }^{17}$ The $\mathrm{A} 2-\mathrm{O}$ interval was measured as the time between the aortic component of the second heart sound and the $O$ point of the apexcardiogram. The pulmonary component (P2) was calculated as the percentage of the aortic component (A2) of the second heart sound (P2/ A2 $\%)$. The third and fourth heart sound amplitudes were measured and were expressed as percentages of the amplitude of the first heart sound ( $3 \mathrm{rd} \%$ and 4th $\%$ ).

Early diastolic filling period, or the distance between mitral valve opening and the $O$ point of the apexcardiogram (Mo-O), was measured by subtracting A2-Mo from the A2-O interval. Because the A2$\mathrm{Mo}$ and A2-O intervals were related to heart rate, we used the regression equations of A2-Mo and A2-O on heart rate in control group $A$ to adjust for heart rate.
The heart rate adjusted intervals were called A2$\mathrm{Mo} \%$ and $\mathrm{A} 2-\mathrm{O} \%$.

\section{STATISTICAL METHODS}

Possible relations were tested with Pitman's nonparametric permutation test, which, when applied for two groups is the same as Fisher's exact test. Pearson's correlation coefficients were calculated for some of the analyses.

We used multiple linear regression technique for multivariate analysis. $P$ values $<0.05$ were regarded as statistically significant.

\section{Results}

Echocardiographic or phonocardiographic findings did not indicate haemodynamically important valve lesions in any of the men. In two of the men with dyspnoea grade 2 we found left ventricular aneurysms on cross sectional echocardiography. They were not excluded because left ventricular dimension and thickness (the only variables that could have been misinterpreted due to the aneurysms) were normal. 
Table 1 Heart rate, blood pressure, echocardiographic left ventricular dimensions and mass (mean (SE))

\begin{tabular}{|c|c|c|c|c|c|}
\hline \multirow[b]{2}{*}{$\begin{array}{l}\text { Dyspnoea grade } \\
\text { Cardiac disease }\end{array}$} & \multicolumn{2}{|c|}{ Control groups } & \multicolumn{2}{|c|}{ Dyspnoeic groups } & \multirow{2}{*}{$\begin{array}{l}\text { Relation } \\
\text { to dyspnoea } \\
\text { grade }(0-4) \\
(n=87) \\
\text { p for trend }\end{array}$} \\
\hline & $\begin{array}{l}(A) \\
\frac{-}{(n=14)}\end{array}$ & $\begin{array}{l}(B) \\
0 \\
+ \\
(n=31)\end{array}$ & $\begin{array}{l}1-3 \\
+ \\
(n=37)\end{array}$ & $\begin{array}{l}4 \\
+ \\
(n=5)\end{array}$ & \\
\hline $\begin{array}{l}\text { Heart rate }(\text { beats } / \mathrm{min}) \\
\text { Systolic BP }(\mathrm{mm} \mathrm{Hg}) \\
\text { Diastolic BP }(\mathrm{mm} \mathrm{Hg}) \\
\text { Mean arterial BP }(\mathrm{mm} \mathrm{Hg}) \\
\text { LV dimension }(\mathrm{mm}) \\
\text { Septal thickness }(\mathrm{mm}) \\
\text { Posterior wall thickness }(\mathrm{mm}) \\
\text { LV mass }(\mathrm{g}) \\
\text { Relative } \mathrm{LV} \text { mass }\left(\mathrm{g} / \mathrm{m}^{2} \mathrm{BSA}\right)\end{array}$ & $\begin{array}{l}55(2) \\
147(4) \\
83(3) \\
104(3) \\
48 \cdot 8(1 \cdot 1) \\
10 \cdot 6(0 \cdot 6) \\
8 \cdot 9(0 \cdot 6) \\
166(12) \\
87(7)\end{array}$ & $\begin{array}{l}58(2) \\
154(4) \\
88(2) \\
110(2) \\
51 \cdot 4(1 \cdot 2) \\
11 \cdot 3(0 \cdot 5) \\
9 \cdot 3(0 \cdot 3) \\
205(12) \\
105(5)\end{array}$ & $\begin{array}{l}58(2) \\
152(4) \\
85(2) \\
108(2) \\
54 \cdot 9(1 \cdot 5) \\
11 \cdot 5(0 \cdot 5) \\
10 \cdot 6(0 \cdot 4) \\
243(19) \\
125(9)\end{array}$ & $\begin{array}{l}83(6) \\
145(5) \\
91(6) \\
109(4) \\
54 \cdot 4(2 \cdot 6) \\
12 \cdot 4(1 \cdot 7) \\
12 \cdot 0(0 \cdot 9) \\
295(40) \\
147(20)\end{array}$ & $\begin{array}{l}0 \cdot 012 \\
0 \cdot 243 \\
0 \cdot 600 \\
0 \cdot 348 \\
0 \cdot 078 \\
0 \cdot 129 \\
0 \cdot 002 \\
0 \cdot 012 \\
0 \cdot 017\end{array}$ \\
\hline
\end{tabular}

\section{DYSPNOEA VERSUS BLOOD PRESSURE AND LEFT} VENTRICULAR MASS

The degree of dyspnoea correlated significantly with left ventricular mass and mass index (table 1). Dyspnoea grade showed a significant relation with posterior wall thickness but not with septal thickness or left ventricular diastolic dimension. Dyspnoea grade was not related to the blood pressure level measured after 45 minutes of supine rest.

DYSPNOEA VERSUS DIASTOLIC TIME INTERVALS The isovolumic relaxation time adjusted for heart rate (A2-Mo\%) tended to be longer (not significantly) in control group $B$ and in the men with mild to moderate dyspnoea than in control group A (table 2). But men with severe dyspnoea had significantly lower A2-Mo\% than men with mild to moderate dyspnoea $(p=0.02)$. A2-O $\%$ was significantly

Table 2 Diastolic time intervals (mean (SE))

\begin{tabular}{|c|c|c|c|c|}
\hline \multirow[b]{2}{*}{$\begin{array}{l}\text { Dyspnoea grade } \\
\text { Cardiac disease }\end{array}$} & \multicolumn{2}{|c|}{ Control groups } & \multicolumn{2}{|c|}{ Dyspnoeic groups } \\
\hline & $\begin{array}{l}(A) \\
0 \\
(n=14)\end{array}$ & $\begin{array}{l}(B) \\
0 \\
+ \\
(n=31)\end{array}$ & $\begin{array}{l}1-3 \\
+ \\
(n=37)\end{array}$ & $\begin{array}{l}4 \\
+ \\
(n=5)\end{array}$ \\
\hline $\begin{array}{l}\text { Heart rate mitral } \\
\text { echocardiogram } \\
\text { (beats/min) } \\
\text { A2-Mo (ms) } \\
\text { A2-Mo\% } \\
\text { Heart rate apex- }\end{array}$ & $\begin{array}{l}63(3) \\
69(7) \\
100(10)\end{array}$ & $\begin{array}{l}63(3) \\
78(4) \\
113(6)\end{array}$ & $\begin{array}{l}60(2) \\
79(5) \\
111(7)\end{array}$ & $\begin{array}{l}79(5) \\
45(8) \\
69(11)\end{array}$ \\
\hline $\begin{array}{l}\text { cardiogram } \\
\text { (beats/min) } \\
\text { A2-O (ms) } \\
\text { A2-O\% } \\
\text { Mo-O (ms) }\end{array}$ & $\begin{array}{l}57(3) \\
153(6) \\
100(3) \\
89(5)\end{array}$ & $\begin{array}{l}60(3) \\
159(4) \\
105(2) \\
85(3)\end{array}$ & $\begin{array}{l}60(2) \\
167(4) \\
112(2) \\
88(6)\end{array}$ & $\begin{array}{l}77(5) \\
133(8) \\
104(3) \\
93(4)\end{array}$ \\
\hline
\end{tabular}

A2-Mo, time from aortic component of second heart sound to mitral opening; A2-Mo\%, A2-Mo as percentage of expected value; A2-O, time from A2 to apexcardiographic O-point; A2-O\%, A2-O as percentage of expected value; Mo-O, time from mitral opening to the O-point. $(p=0.01)$ prolonged in men with lower grade dyspnoea than in the control group A. In men with

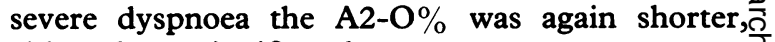
although not significantly so.

DYSPNOEA COMPARED WITH INDICES OF LEFT VENTRICULAR EARLY FILLING, HEART SOUNDS, ATRIAL SIZE, AND INDICES OF PULMONARY ARTERY PRESSURE

There was a significant relation between dyspnoea and atrial emptying index, rapid filling wave

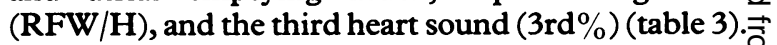
Dyspnoea was also significantly related to the fourth 3 heart sound ( 4 th $\%$ ), left atrial diameter, left atrial index (left atrial dimension adjusted for body surface area), pulmonary component of the second heart sound, and the diameter of the right ventricle.

Dyspnoea grade correlated with the absolute? amplitudes of the first heart sound $(r=-0.25$, $p=0.04)$ and with the third heart sound $(r=0.39$, $\mathrm{p}=0.003$ ), but not with the absolute amplitude of the fourth heart sound $(r=0.08, N S)$. The amplitude of the third heart sound was related to the rapid filling wave $(\mathrm{RFW} / \mathrm{H})$, both with $(3 \mathrm{rd} \%)$ $(r=0.60, p<0.0001)$ and without $(r=0.56$, $\mathrm{p}<0.0001$ ) adjustment for the amplitude of the firster heart sound. The absolute amplitude of the thirds heart sound was not related to the amplitude of then first heart sound, whereas the absolute fourth heart sound amplitude was $(r=0.28, p=0.03)$.

LEFT VENTRICULAR WALL THICKNESS AND MASS COMPARED WITH BLOOD PRESSURE, CLINICAL HISTORY, AND INDICES OF DIASTOLIC LEFT VENTRICULAR FUNCTION

Left ventricular mass index (but not posterior wall $\mathbb{Q}$ thickness) was significantly related with systolic $(\mathrm{r}=0.41, \mathrm{p}=0.002)$, diastolic $(\mathrm{r}=0.36, \mathrm{p}=0.005)$, and mean $(r=0.44, p=0.0004)$ arterial blood pres- 
Table 3 Indices of left ventricular distensibility and pulmonary artery pressure (mean (SE))

\begin{tabular}{|c|c|c|c|c|c|}
\hline \multirow[b]{2}{*}{$\begin{array}{l}\text { Dyspnoae grade } \\
\text { Cardiac disease }\end{array}$} & \multicolumn{2}{|c|}{ Control groups } & \multicolumn{2}{|c|}{ Dyspnoeic groups } & \multirow[b]{2}{*}{$\begin{array}{l}\text { Relation } \\
\text { to dyspnoea } \\
\text { grade }(0-4) \\
(n=87) \\
\text { p for trend }\end{array}$} \\
\hline & $\begin{array}{l}(A) \\
0 \\
(n=14)\end{array}$ & $\begin{array}{l}(B) \\
0 \\
+ \\
(n=31)\end{array}$ & $\begin{array}{l}1-3 \\
+ \\
(n=37)\end{array}$ & $\begin{array}{l}4 \\
+ \\
(n=5)\end{array}$ & \\
\hline $\begin{array}{l}\text { Left ventricular: } \\
\text { Peak } \mathrm{dD} / \mathrm{dt}(\mathrm{cm} / \mathrm{s}) \\
\text { Time to peak } \mathrm{dD} / \mathrm{dt}(\mathrm{ms})\end{array}$ & $\begin{array}{l}9 \cdot 4(0 \cdot 7) \\
185(11)\end{array}$ & $\begin{array}{l}9 \cdot 5(0 \cdot 5) \\
162(10)\end{array}$ & $\begin{array}{l}9 \cdot 6(0 \cdot 5) \\
167(10)\end{array}$ & $\begin{array}{l}8 \cdot 1(0 \cdot 7) \\
136(13)\end{array}$ & $\begin{array}{l}0.154 \\
0.493\end{array}$ \\
\hline $\begin{array}{l}\text { Posterior wall: } \\
\text { Peak - dD/dt (cm/s) } \\
\text { Time to peak } \mathrm{dD} / \mathrm{dt}(\mathrm{ms}) \\
\text { Atrial emptying index } \\
\text { RFW/H }(\%) \\
\text { 3rd\% } \\
\text { 4th\% } \\
\text { Left atrial dimension (mm) } \\
\text { Relative left atrial dimension }\end{array}$ & $\begin{array}{l}6 \cdot 8(0 \cdot 5) \\
183(12) \\
0 \cdot 88(0 \cdot 04) \\
7 \cdot 5(0 \cdot 7) \\
1(1) \\
12(3) \\
39 \cdot 8(1 \cdot 7)\end{array}$ & $\begin{array}{l}6 \cdot 3(0 \cdot 5) \\
151(14) \\
0 \cdot 85(0 \cdot 04) \\
8 \cdot 1(0 \cdot 9) \\
1(0) \\
10(1) \\
43 \cdot 3(1 \cdot 1)\end{array}$ & $\begin{array}{l}7 \cdot 8(0 \cdot 4) \\
149(8) \\
0 \cdot 79(0 \cdot 04) \\
6 \cdot 1(0 \cdot 7) \\
4(1) \\
15(3) \\
45 \cdot 9(1 \cdot 0)\end{array}$ & $\begin{array}{l}6 \cdot 4(0 \cdot 8) \\
134(14) \\
0 \cdot 54(0 \cdot 15) \\
15 \cdot 1(4 \cdot 3) \\
39(25) \\
47(31) \\
52 \cdot 4(2 \cdot 9)\end{array}$ & $\begin{array}{l}0.909 \\
0.404 \\
0.025 \\
0.036 \\
0.008 \\
0.010 \\
0.001\end{array}$ \\
\hline $\begin{array}{l}\quad\left(\mathrm{mm} / \mathrm{m}^{2} \mathrm{BSA}\right) \\
\text { P2/A2 }(\%) \\
\text { Right ventricular dimension }(\mathrm{mm})\end{array}$ & $\begin{array}{l}21 \cdot 3(1 \cdot 0) \\
10(7) \\
21 \cdot 6(2 \cdot 8)\end{array}$ & $\begin{array}{l}22 \cdot 3(0 \cdot 6) \\
28(8) \\
20 \cdot 3(1 \cdot 4)\end{array}$ & $\begin{array}{l}23 \cdot 3(0 \cdot 5) \\
32(8) \\
20 \cdot 4(1 \cdot 5)\end{array}$ & $\begin{array}{l}26 \cdot 4(1 \cdot 3) \\
97(62) \\
32 \cdot 3(3 \cdot 1)\end{array}$ & $\begin{array}{l}0.024 \\
0.032 \\
0.022\end{array}$ \\
\hline
\end{tabular}

BSA, body surface area; $\mathrm{dD} / \mathrm{dt}$, rate of change of dimension (during left ventricular filling period); P2/A2, pulmonary component as percentage of aortic component of second heart sound; $R W F / H$, amplitude of rapid filling wave as percentage of total height of apexcardiogram; 3rd\%, third heart sound amplitude as percentage of first sound amplitude; 4th\%, fourth heart sound amplitude as percentage of first sound amplitude.

sure and with a history of treated hypertension $(\mathrm{r}=0.39, \mathrm{p}=0.003)$.

Left ventricular posterior wall thickness $(r=0.34$, $\mathrm{p}=0.005)$ and left ventricular mass index $(\mathrm{r}=0.38$, $\mathrm{p}=0.007$ ) were related to a clinical history of myocardial infarction. Posterior wall thickness was also related to a history of angina pectoris $(r=0.31$, $\mathrm{p}<0.01)$, whereas mass index was not $(\mathrm{r}=0.17$, $\mathrm{p}=0.205$ ).

The left atrial dimension correlated with posterior wall thickness $(r=0.44, p=0.0002)$ and even better with left ventricular mass index $(r=0.57$, $p=0.0001)$ as did the left atrial index $(r=0.48$, $\mathrm{p}=0.0002)$. Also the pulmonary component (P2/ A2\% $(r=0.32, p=0.027)$ correlated positively with left ventricular mass index, while there was an inverse correlation between the latter and atrial emptying index $(r=-0.36, p=0.013)$. Neither diastolic time intervals, nor the third or fourth heart sounds, correlated significantly with mass.

\section{MULTIVARIATE ANALYSES OF THE RELATION BETWEEN DYSPNOEA AND FUNCTIONAL \\ VARIABLES}

Associations between non-invasive measurements and clinical variables with dyspnoea were evaluated by multivariate analyses.

The first step was to examine the relation between dyspnoea grade and a history of angina pectoris, myocardial infarction, tobacco consumption, treatment for hypertension, blood pressure, heart size and pulmonary congestion at $x$ ray examination, atrial fibrillation and $Q$ waves in the electrocardiogram, and vital capacity. Angina pectoris, pulmonary con-

Table 4 The results from univariate and multivariate analysis of the contribution to the explanation of dyspnoea grade variance

\begin{tabular}{|c|c|c|c|c|c|c|}
\hline & \multicolumn{3}{|c|}{ Univariate analysis } & \multicolumn{3}{|c|}{ Multivariate analysis } \\
\hline & $r$ & $p$ & $\begin{array}{l}\text { Proportion } \\
\text { of explained } \\
\text { variance }\end{array}$ & $\begin{array}{l}\text { Additional } \\
\text { proportion } \\
\text { of explained } \\
\text { variance }\end{array}$ & $p$ & $\begin{array}{l}\text { Cumulative } \\
\text { proportion } \\
\text { of explained } \\
\text { variance }\end{array}$ \\
\hline $\begin{array}{l}\text { Angina pectoris } \\
\text { Pulmonary congestion } \\
\text { Electrocardiographic } Q\end{array}$ & $\begin{array}{l}0.51 \\
0.46\end{array}$ & $\begin{array}{r}<0.0001 \\
0.0003\end{array}$ & $\begin{array}{l}0.26 \\
0 \cdot 21\end{array}$ & $\begin{array}{l}0 \cdot 30^{\star} \\
0 \cdot 15\end{array}$ & $\begin{array}{l}0.0001 \\
0.0001\end{array}$ & $\begin{array}{l}0.30 \\
0.45\end{array}$ \\
\hline $\begin{array}{l}\text { waves } \\
\text { Left atrium (mm) } \\
\text { Atrial emptying index }\end{array}$ & $\begin{array}{r}0.39 \\
0.36 \\
-0.26\end{array}$ & $\begin{array}{l}0.0012 \\
0.0010 \\
0.0252\end{array}$ & $\begin{array}{l}0 \cdot 15 \\
0 \cdot 13 \\
0 \cdot 07\end{array}$ & $\begin{array}{l}0.06 \\
0.04 \\
0.02\end{array}$ & $\begin{array}{l}0.0017 \\
0 \cdot 0141 \\
0.0638\end{array}$ & $\begin{array}{l}0.51 \\
0.55 \\
0.57\end{array}$ \\
\hline
\end{tabular}

*The discrepancy to univariate analysis is the result of two missing values in the multivariate analysis. 
To evaluate whether any diastolic variable is 0 associated with early heart failure, we tested the $\dot{\omega}$ differences in mean values between mild to moderate dyspnoea (grade 1-3 group) and the control group A. As already stated, the $\mathrm{A} 2-\mathrm{O} \%$ was prolonged $(\mathrm{p}<0.02)$, indicating a prolonged relaxation/early ${ }_{\bar{Z}}^{-}$ filling period in mild to moderate dyspnoea. Also the posterior wall thickness was significantly increasedô $(p<0.03)$ as was the sum of septal and posterior wall thicknesses $(p<0.02)$, while septal thickness aloneo. was not significantly increased. The left atrial dimen- sion was increased $(p<0.003)$. On the other hand, indices of severe heart failure, such as an increased pulmonary component, the third heart sound, rapido filling wave, and right ventricular dimension, wereo

Fig 2 Mean dyspnoea grade in groups of men according to left atrial size (quintiles) and clinical involvement. The latter was indicated by the presence of $Q$ waves in the electrocardiogram, pulmonary congestion on $x$ ray, and a history of angina pectoris (one point for each). The points were summed up in a clinical score shown along the left horizontal axis.

gestion, and $Q$ waves accounted for $47 \%$ of the variation in grade of dyspnoea. They were the only factors that contributed to the explanation when the other variables were accounted for.

In a second step the contributions of posterior wall thickness, left ventricular mass, and the variables of diastolic function were examined. These variables accounted for $16 \%$ of the variation in the grade of dyspnoea. Left atrial size and atrial emptying index were the only independent significant variables.

In the third and last step the three independent significant factors from step 1 and the two from step 2 were introduced into a multivariate analysis. The left half of table 4 shows the results of the univariate analysis. The variables are listed in order of univariate correlation with dyspnoea grade. The right half of table 4 shows the contribution of each variable and the cumulative explanation of dyspnoea grade variance. In order of significance the factors not significantly different in men with dyspnoea grade 1-3 and the group A controls.

\section{A COMPARISON OF DIASTOLIC AND SYSTOLIC FUNCTION}

Since systolic dysfunction may explain signs of increased filling pressures, the relation between theo grade of dyspnoea and left atrial dimension was evaluated by multiple regression analyses, taking the effect of fractional shortening and end systolicio dimension into account. Significant contributions to the explanation of dyspnoea grade were still obtainedo from left atrial dimension when considering: $(a)$ left? atrial dimension $(p=0.01)$ and fractional shorten $=0$ ing $(p=0.002) ;(b)$ left atrial dimension $(p=0.02)$ and end systolic dimension $(p=0.02)$; (c) left atriak dimension $(p=0.01)$, fractional shortening 0 $(p<0.04)$, and end systolic dimension $(p=N S)$. N

\section{Discussion}

In the present study cardiac dyspnoea was related to left ventricular hypertrophy and to diastolic ${ }_{-0}^{-}$ abnormalities, some of which were primary and others which may have been secondary to systolic? dysfunction. Diastolic and systolic function of the heart are closely related, both on the atrial ${ }^{18}$ and the ventricular $^{19}$ levels. Diastolic abnormalities mayo 
cause congestive heart failure in the absence of systolic dysfunction. ${ }^{89}$ Nevertheless, diastolic and systolic function are often abnormal simultaneously, ${ }^{19}$ and both may increase filling pressures. It was therefore necessary to take the degree of systolic impairment into account when determining the importance of diastolic abnormalities to the degree of cardiac dyspnoea.

\section{LEFT VENTRICULAR HYPERTROPHY}

In the Framingham study the prevalence of echocardiographic left ventricular hypertrophy was $23.7 \%$ among men who were about 70 years old. ${ }^{20}$ In the present study an increase in left ventricular wall thickness was responsible for the increase in left ventricular mass in men with dyspnoea. An increased left ventricular dimension also contributed to the increasing left ventricular mass, but left ventricular dimension per se was not significantly related to dyspnoea grade. Left ventricular mass was significantly correlated with blood pressure, indicating that hypertension contributed to congestive heart failure in the present study group, as it did in the Framingham study. ${ }^{21}$ In coronary heart disease there is left ventricular hypertrophy caused by an increase in the thickness of non-infarcted areas to compensate for myocardial loss elsewhere.$^{22}$ It has been suggested that increased left ventricular wall thickness in coronary or hypertensive heart disease causes filling problems, ${ }^{23}$ and that diastolic function abnormalities are related to wall thickness. ${ }^{24}$ Nevertheless, in athletes with a corresponding degree of hypertrophy diastolic variables were normal. ${ }^{24}{ }^{25}$ It has therefore been suggested that abnormalities of diastolic function, as seen in pathological hypertrophy, are partly the result of factors other than the cardiac hypertrophic process as such. ${ }^{25}$ Age is such a factor. Age influences the diastolic properties of the heart, ${ }^{26-28}$ and may have a role in the development of symptoms of heart failure in the elderly. ${ }^{29}$ This factor cannot have influenced our results because all the men we studied were the same age.

\section{LEFT VENTRICULAR RELAXATION AND EARLY FILLING PROPERTIES}

In addition to signs of left ventricular hypertrophy, men with mild to moderate dyspnoea had an increased $\mathrm{A} 2-\mathrm{O} \%$, which accords with previous results indicating that prolongation of the A2-O interval is an early indication of myocardial dysfunction. ${ }^{12}$ A prolonged A2-O interval or isovolumic relaxation period may be caused by left ventricular hypertrophy or incoordinate left ventricular relaxation secondary to coronary artery disease, although the duration of diastolic time intervals is not always a valid reflection of left ventricular relaxation when there is pressure or volume overload. ${ }^{30}$ Left ventricular relaxation probably extends beyond the isovolumic phase and contributes to left ventricular filling, ${ }^{30}$ and its duration may therefore be approximated by the A2-O interval, which may be regarded as a measure of the time required for left ventricular pressure to reach its nadir. ${ }^{31}$ We expected that, after adjustment for heart rate, the A2-Mo and A2-O intervals would increase with increasing degree of dyspnoea because of impaired left ventricular relaxation. However, in the group with severe dyspnoea an increased atrial pressure was likely to have caused early opening of the mitral leaflets ${ }^{31}$ and a short left ventricular filling time. ${ }^{32}$ If so, a further decrease in $\mathrm{A} 2-\mathrm{Mo} \%$ and $\mathrm{A} 2-\mathrm{O} \%$ would be expected in the most dyspnoeic group. This turned out to be the case.

Dyspnoea grade was related to the relative amplitude of the third heart sound ( $3 \mathrm{rd} \%$ ) and to the rapid filling wave which were grossly abnormal in severe heart failure. The third heart sound is an early diastolic event of obscure pathogenesis, ${ }^{33}$ which, when heard as a gallop sound in myocardial infarction, is related to raised pulmonary artery pressure and associated with a poor prognosis. ${ }^{34}$ In the present study, and others, ${ }^{26}$ a relation was found between the third sound and the rapid filling wave amplitudes. We used the same equipment to record the third sound in all men. The influence of $\operatorname{age}^{26}{ }^{27}$ as a confounding factor could be disregarded, but not inherent differences in thoracic auditory transmission. Therefore, the first heart sound was used as a reference. The first heart sound could be influenced by contractile performance of the left ventricle-that is the systolic performance. This hypothesis was supported by a significant inverse correlation between the first heart sound and the dyspnoea grade. The amplitude of the third heart sound was not only correlated with the dyspnoea grade but also did not correlate significantly with the first heart sound. Moreover, an increase of the third heart sound is not likely to have been caused by good thoracic transmission, since the men with the most severe dyspnoea had a larger body mass index than the control group. These findings indicate that the relation between dyspnoea grade and the third heart sound was not caused by bias.

Among men with severe dyspnoea (grade 4) there was a reduced atrial emptying index, and a tendency (trend not significant) towards a lower left ventricular filling rate as well as to a slower rate of posterior wall thinning.

In the absence of mitral stenosis a reduced atrial emptying index (indicative of a reduced rate of early diastolic filling) is an expression of impaired left ventricular filling. ${ }^{816}$ Although the aortic root motion may be influenced by several factors, it seems to be 
governed mainly by the rate of change in left atrial volume. ${ }^{16}$ Rapid early diastolic wall thinning is likely to be a manifestation of relaxation and is a major determinant of left ventricular filling. ${ }^{35} \mathrm{~A}$ reduced diastolic filling rate has been reported in homogeneous groups of patients with coronary ${ }^{1636}$ and hypertensive $^{2324}$ heart disease, but other studies, like ours, reported no significant difference between controls and patients with left ventricular disease, ${ }^{37}$ angina pectoris, ${ }^{38}$ or coronary disease with no systolic dysfunction..$^{39}$ Atrial pressure may influence the atrial emptying index, as well as the peak change in left ventricular dimension and wall thinning, ${ }^{4041}$ which are also indices directly associated with myocardial contractility..$^{19}$

\section{LEFT VENTRICULAR DISTENSIBILITY AND}

ATRIAL AND PULMONARY ARTERY PRESSURES

Left ventricular distensibility, often used interchangeably with the term compliance, is the change in volume relative to a change in pressure, ${ }^{42}$ a relation that we could not measure non-invasively. Indirect non-invasive tests of distensibility are based on the relative power of the left atrium needed to force the blood into the left ventricle. ${ }^{47}$ However, with severe left ventricular failure, not only atrial failure, but also the raised filling pressure may cause a "paradoxical" decrease of echocardiographic (Caidahl et al, unpublished), Doppler, ${ }^{43}$ and apexcardiographic ${ }^{44}$ signs of the previously increased atrial contribution to left ventricular filling. This phenomenon complicates the non-invasive study of left ventricular distensibility in heart failure. In this study dyspnoea grade was related to an increased fourth heart sound relative to the first heart sound. We did not feel confident in drawing any conclusions from this fourth/first heart sound ratio, however, because the amplitude of the fourth heart sound in itself did not correlate with dyspnoea grade.

The left atrial dimension may also be regarded as an indirect index of distensibility of the left ventricle ${ }^{45}$ and it does not have the drawbacks mentioned above. When left ventricular distensibility is impaired the atrial contribution to left ventricular filling is augmented ${ }^{46}$ and the atrium becomes enlarged. A vigorous atrial contraction may enable the left ventricle to be filled despite an increased end diastolic pressure, and this permits pulmonary capillary pressure to remain at a low level. ${ }^{47}$ Finally, with atrial failure, the pulmonary capillary pressure will increase and dyspnoea will ensue or be aggravated.

Systolic dysfunction can also raise filling pressure. The relative influence of diastolic and systolic dysfunction on atrial distension must therefore be considered. In multivariate analyses the left atrial dimension contributed significantly to the explana- tion of cardiac dyspnoea even when the importance of ${ }_{C}$ fractional shortening and end systolic dimension $\Rightarrow$ were taken into account. This indicates that the left $\stackrel{\oplus}{?}$ atrial distension may be caused by a raised filling pressure secondary to diastolic dysfunction.

The grade of dyspnoea was related to the atrial dimension, and the latter was also correlated with left $\stackrel{\mathbb{Q}}{\varnothing}$ ventricular wall thickness. There was a significant $\$$ increase of left atrial size in mild to moderate grade $\vec{\circ}$ dyspnoea and the dyspnoea grade increased with left atrial size. However, atrial enlargement was accom- $\vec{\omega}$ panied by an increase in the pulmonary component $\frac{\Omega}{2}$ calculated as a percentage of the aortic component of the second heart sound and an enlarged right ven- $c$ tricular dimension only in the most severe dyspnoea $\omega$ grade reflecting a raised pulmonary artery pressure in this group.

\section{CLINICAL IMPLICATIONS}

Diastolic left ventricular abnormalities were more common the more advanced the degree of dyspnoea $\stackrel{\rho}{\supset}$ in the present study, supporting the concept that left $\vec{\bullet}$ ventricular diastolic function is important in the $\infty$ generation of dyspnoea in congestive heart failure. Concomitant systolic dysfunction may be the primary event in many cases, causing raised filling pressures. Nevertheless, multivariate analyses showed that diastolic impairment causing an enlarged left atrium made a significant independent contribution to cardiac dyspnoea when the contribution from systolic function was taken into account. Increased left atrial dimension, myocardial hypertrophy, and prolonged $\mathrm{A} 2-\mathrm{O} \%$ in mild to moderate dyspnoea also support this concept, since we have already found ${ }^{11}$ that dyspnoea grade 1-3 was associated with normal fractional shortening. As a $\frac{0}{3}$ consequence, not only in individuals with hypertrophic cardiomyopathy, ${ }^{48}$ but also in patients with $ᄋ$ heart failure, therapeutic measures ${ }^{6} 49$ aimed at improving diastolic function may be useful. Drug 응 trials are required to establish the potential patho- $\rightarrow$ physiological and therapeutic value of correcting diastolic abnormalities in congestive heart failure.

This study was supported by grants from the $N$ Swedish National Association against Heart and $\underset{\mathrm{C}}{\stackrel{\circ}{ }}$ Chest Diseases, the Gothenburg Medical Society, $\omega$ Sahlgren's Foundations, Swedish Medical Research Council, Queen Victoria and King Gustav V Foun- $\stackrel{\circ}{\circ}$ dation, Förenade Liv Mutual Group Life Insurance $\stackrel{\Phi}{\rightleftharpoons}$ Company, Stockholm, Sweden, and Gothenburg University.

\section{References}

1 Wikstrand J, Berglund G, Wilhelmsen L, Wallentin I. $§$ 
Value of systolic and diastolic time intervals. Studies in normotensive and hypertensive 50-year-old men and in patients after myocardial infarction. Br Heart $J$ 1978;40:256-67.

2 Hartford M, Wikstrand J, Wallentin I, Ljungman S, Wilhelmsen L, Berglund G. Diastolic function of the heart in untreated primary hypertension. Hypertension 1984;6:329-38.

3 Franciosa JA. Epidemiologic patterns, clinical evaluation, and long-term prognosis in chronic congestive heart failure. $A m J$ Med 1986;80(suppl 2B):14-21.

4 Takenaka K, Dabestani A, Gardin JM, et al. Pulsed Doppler echocardiographic study of left ventricular filling in dilated cardiomyopathy. Am J Cardiol 1986;58:143-7.

5 Emanuelsson $\mathrm{H}$, Caidahl $\mathrm{K}$, Hjalmarsson $\AA$, et al. Comparison of atrial pacing and the cold pressor test in patients with angina pectoris. Clin Sci 1984; 67:601-11.

6 Vedin A, Wikstrand J, Wilhelmsson C, Wallentin I. Left ventricular function and beta-blockade in chronic ischaemic heart failure. Double-blind, crossover study of propranolol and penbutolol using noninvasive techniques. Br Heart J 1980;44:101-7.

7 Bristow JD, van Zee BE, Judkins MP. Systolic and diastolic abnormalities of the left ventricle in coronary artery disease. Studies in patients with little or no enlargement of ventricular volume. Circulation 1970; 42:219-28.

8 Hamilton Dougherty A, Naccarelli GV, Gray EL, Hicks $\mathrm{CH}$, Goldstein HA. Congestive heart failure with normal systolic function. $A m J$ Cardiol 1984;54:778-82.

9 Soufer R, Wohlgelernter D, Vita NA, et al. Intact systolic left ventricular function in clinical congestive heart failure. Am J Cardiol 1985;55:1032-6.

10 Caidahl K, Svärdsudd K, Eriksson H, Wilhelmsen L. Relation of dyspnoea to left ventricular wall motion disturbances in a population of 67-year-old men. $\mathrm{Am}$ J Cardiol 1987;59:1277-82.

11 Caidahl K, Eriksson H, Hartford M, Wikstrand J, Wallentin I, Svärdsudd K. Dyspnoea of cardiac origin in 67 year old men: (1) relation to systolic left ventricular function and wall stress. The study of men born in 1913. Br Heart $J$ 1988;59:319-28.

12 Eriksson H, Caidahl K, Larsson B, et al. Cardiac and pulmonary causes of dyspnoea - validation of a scoring test for clinical-epidemiological use. The study of men born in 1913. Eur Heart $J$ 1987;8:1007-14.

13 Rose GA, Blackburn H, Gillum RF, Prineas RJ. Cardiovascular survey methods (Monograph No 56.) 2nd ed. Geneva: World Health Organization, 1982: 123-68.

14 Hartford M, Wikstrand J, Wallentin I, Ljungman S, Wilhelmsen L, Berglund G. Left ventricular mass in middle-aged men. Relationship to blood pressure, sympathetic nervous activity, hormonal and metabolic factors. Clin Exp Hypertens 1983;5: 1429-51.

15 Teichholtz LE, Kreulen T, Herman MV, Gorlin R. Problems in echocardiographic volume determinations: echocardiographic-angiographic correlations in the presence or absence of asynergy. Am $J$ Cardiol 1976;37:7-11.

16 Wasserman AG, Meyer JF, Ross AM. The relationship of pulmonary artery wedge pressure to the posterior aortic wall echocardiogram in patients free of obstructive mitral valve disease. Am Heart J 1980;100:500-5.

17 Waagstein F, Hjalmarson $\AA$, Varnauskas E, Wallentin I. Effect of chronic beta-adrenergic receptor blockade in congestive cardiomyopathy. Br Heart J 1975;37: $1022-36$

18 Toma Y, Matsuda Y, Moritani K, Ogawa H, Matsuzaki $M$, Kusukawa $R$. Left atrial filling in normal human subjects: relation between left atrial contraction and left atrial early filling. Cardiovasc Res 1987;21:255-9.

19 Bahler RC, Vrobel TR, Martin P. The relation of heart rate and shortening fraction to echocardiographic indexes of left ventricular relaxation in normal subjects. J Am Coll Cardiol 1983;2:926-33.

20 Savage DD, Garrison RJ, Kannel WB, et al. The spectrum of left ventricular hypertrophy in a general population sample: the Framingham study. Circulation 1987;75(suppl I)I-26-33.

21 Kannel WB, Savage DD, Castelli WP. Cardiac failure in the Framingham study: twenty year follow-up. In: Braunwald E, Mock MB, Watson JT, eds. Congestive heart failure. Current research and clinical applications. New York: Grune and Stratton, 1982:15-30.

22 Rubin SA, Fishbein MC, Swan HJC, Rabines A. Compensatory hypertrophy in the heart after myocardial infarction in the rat. J Am Coll Cardiol 1983; 1:1435-41.

23 Gibson DG, Traill TA, Hall RJC, Brown DJ. Echocardiographic features of secondary left ventricular hypertrophy. Br Heart J 1979;41:54-9.

24 Shapiro LM, McKenna WJ. Left ventricular hypertrophy. Relation of structure to diastolic function in hypertension. Br Heart $J$ 1984;51:637-42.

25 Colan SD, Sanders SP, MacPherson D, Borow KM. Left ventricular diastolic function in elite athletes with physiologic cardiac hypertrophy. J Am Coll Cardiol 1985;6:545-9.

26 Reddy PS, Haidet K, Meno F. Relation of intensity of cardiac sounds to age. Am J Cardiol 1985;55:1383-8.

27 Iskandrian AS, Hakki A-H. Age-related changes in left ventricular diastolic performance. Am Heart $J$ 1986; 112:75-8.

28 Van de Werf F, Geboers J, Kesteloot H, de Geest H, Barrios L. The mechanism of disappearance of the physiologic third heart sound with age. Circulation 1986;73:877-84.

29 Luchi RJ, Snow E, Luchi JM, Nelson CL, Pircher FJ. Left ventricular function in hospitalized geriatric patients J Am Geriatr Soc 1982;30:700-5.

30 Gamble WH, Shaver JA, Alvares RF, Salerni R, Reddy PS. A critical appraisal of diastolic time intervals as a measure of relaxation in left ventricular hypertrophy. Circulation 1983;68:76-87.

31 Mattheos M, Shapiro E, Oldershaw PJ, Sacchetti R, Gibson DG. Non-invasive assessment of changes in left ventricular relaxation by combined phono-, echo-, and mechanocardiography. Br Heart J 1982; 47:253-60. 
32 Vancheri FS, Barberi O, Rugiano A, Amico C. Noninvasive assessment of changes in left ventricular diastolic time intervals after acute blood volume reduction in haemodialysis. Eur Heart $J$ 1986;7: 871-6.

33 Prewitt T, Gibson D, Brown D, Sutton G. The 'rapid filling wave' of the apex cardiogram. Its relation to echocardiographic and cineangiographic measurements of ventricular filling. $B r$ Heart $J$ 1975; 37:1256-62.

34 Riley CP, Russell RO, Rackley CE. Left ventricular gallop sound and acute myocardial infarction. $\mathrm{Am}$ Heart $J$ 1973;86:598-602.

35 Gibson DG, Greenbaum R, Marier DL, Brown DJ. Clinical significance of early diastolic changes in left ventricular wall thickness. Eur Heart $J$ 1980;1(suppl A):157-63.

36 Hui WKK, Gibson DG. Mechanisms of reduced left ventricular filling rate in coronary artery disease. $\mathrm{Br}$ Heart $J$ 1983;50:362-71.

37 Gibson DG, Brown D. Measurement of instantaneous left ventricular dimension and filling rate in man, using echocardiography. Br Heart J 1973;35:1141-9.

38 Pouleur H, Rousseau MF, van Eyll C, Gurné O, Hanet C, Charlier AA. Impaired regional diastolic distensibility in coronary artery disease: relations with dynamic left ventricular compliance. Am Heart $J$ 1986;112:721-8.

39 Inouye IK, Hirsch AT, Loge D, Tabau JF, Massie BM. Left ventricle filling is usually normal in uncomplicated coronary disease. Am Heart J 1985;110: 326-31.

40 Askenazi J, Koenigsberg DI, Ribner HS, Plucinski D, Silverman IM, Lesch M. Prospective study comparing different echocardiographic measurements of pulmonary capillary wedge pressure in patients with organic heart disease other than mitral stenosis.
J Am Coll Cardiol 1983;2:919-25.

41 Ishida $Y$, Meisner JS, Tsujioka K, et al. Left ventricular filling dynamics: influence of left ventricular relaxa- $-\stackrel{S}{-}$ tion and left atrial pressure. Circulation 1986;74: 187-96.

42 Mirsky I. Assessment of passive elastic stiffness of $\frac{\bar{y}}{\frac{5}{2}}$ cardiac muscle: mathematical concepts, physiologic and clinical considerations, directions of future research. Prog Cardiovasc Dis 1976;18:277-308.

43 Choong CY, Herrmann HC, Weyman AE, Fifer MA. $\overrightarrow{0}$ Doppler indices of left ventricular diastolic function are dependent on filling pressure in man (Abstract). $J \vec{\omega}$ Am Coll Cardiol 1987;9(suppl A):198A.

44 Swedberg K, Hjalmarson $\AA$, Waagstein F, Wallentin $I .7$ Beneficial effects of long-term beta-blockade in con- $]$ gestive cardiomyopathy. Br Heart J 1980;44:117-33. $\omega$

45 Hamby RI, Zeldis SM, Hoffman I, Sarli P. Left atrialw size and left ventricular function in coronary artery 6 disease: an echocardiographic-angiographic corre-윽 lative study. Cathet Cardiovasc Diagn 1982;8:173-83.

46 Miyatake K, Okamoto M, Kinoshita N, et al. Augmen- 3 tation of atrial contribution to left ventricular inflow with aging as assessed by intracardiac Doppler flow-옥 metry. Am J Cardiol 1984;53:586-9.

47 Brauwald E, Frahm CJ. Studies on Starlings law of the heart. IV. Observations on the hemodynamic func-. tions of the left atrium in man. Circulation 1961; 24:633-42.

48 Bonow RO, Dilsizian V, Rosing DR, Maron BJ, Bacharach SL, Green MV. Verapamil-induced@ improvement in left ventricular diastolic filling and్ㅛ increased exercise tolerance in patients with hypertrophic cardiomyopathy: short- and long-termō effects. Circulation 1985;72:853-64.

49 Lefkowitz CA, Moe GW, Armstrong PW. Calcium? antagonists: new therapy for congestive heart failure? Chest 1987;91:1-3. 